\title{
Preparation and Characterization of CuO Nano Particles Using Sol-Gel Method and Its Application as $\mathrm{CuOl} \mathrm{Al}_{2} \mathrm{O}_{3}$ Supported Catalyst
}

\author{
Mohammed Sulieman Ali Eltoum ${ }^{1, ~ *, ~ R u f a a ~ M o h a m e d ~ O s m a n ~ N a s r ~}{ }^{1}$, \\ Hager Mohamed Ahmed Omer ${ }^{2}$ \\ ${ }^{1}$ Department of Chemistry, Sudan University of Science and Technology, Khartoum, Sudan \\ ${ }^{2}$ Chemistry Department, College of Science, Jazan University, KSA
}

Email address:

abotrteel74@gmail.com (M. S. A. Eltoum)

${ }^{*}$ Corresponding author

\section{To cite this article:}

Mohammed Sulieman Ali Eltoum, Rufaa Mohamed Osman Nasr, Hager Mohamed Ahmed Omer. Preparation and Characterization of CuO Nano Particles Using Sol-Gel Method and Its Application as $\mathrm{CuO} / \mathrm{Al}_{2} \mathrm{O}_{3}$ Supported Catalyst. American Journal of Nano Research and Applications. Vol. 8, No. 2, 2020, pp. 16-21. doi: 10.11648/j.nano.20200802.11

Received: March 23, 2020; Accepted: May 6, 2020; Published: May 14, 2020

\begin{abstract}
In this research copper oxide (CuO) nanoparticles were prepared by sol gel method. In this method $\mathrm{CuCl}_{2} \cdot 2 \mathrm{H}_{2} \mathrm{O}$ was used as precursor, the obtained $\mathrm{CuO}$ nanoparticles were further supported by alumina to produce copper oxide support on alumina catalyst, the copper oxide nanoparticle and the catalyst were characterized using different analytical techniques such as titrimetric method, x-ray diffraction (XRD), Scanning Electron Microscope (SEM) and the catalyst was applied in the synthesis of tetraethyl orthosilicate (TEOS). The obtained results indicated the formation of copper oxide nanoparticles and copper oxide supported in alumina catalyst in high quality, also the catalyst increased the rate of formation of tetraethyl orthosilicate (TEOS).
\end{abstract}

Keywords: Copper Oxide, Nano Particles, Sol-Gel, Orthosilicate, Catalyst

\section{Introduction}

The oxides of transition metals are an important class of semiconductors, which have applications in magnetic storage media, solar energy transformation, electronics and catalysis [1] Among the oxides of transition metals, copper oxide nanoparticles are of special interest, it is a semiconductor material and has a natural abundance of starting material, It has wide applications, such as in solar cell technology, field emission, magnetic storage media, lithium ion batteries, gas sensing, and drug delivery, magnetic resonance imaging, and field emission devices. Varieties of physical and chemical methods have been proposed to synthesize $\mathrm{CuO}$ nanoparticles (CuO-NPs) [2]. $\mathrm{CuO}$-NPs belong to monoclinic structure system with the brownish-black appearance [3]. They find their significant role in antibacterial agents to fabrics [4].

The activity of nano materials as a catalyst depends mostly on the nano powder material size, morphology and specific surface area of the prepared materials. Due to the potentiality of $\mathrm{CuO}$, it acts as a catalyst; whereas all metal oxides are not useful for the catalytic activity. as like Fenton's reagent $\mathrm{CuO}$ combined with another metal oxide like $\mathrm{CeO}_{2}$.

In this paper, we have synthesized $\mathrm{CuO}$ nanoparticles by simple aqueous precipitation method with size $9-10 \mathrm{~nm}$. The synthesized nanoparticles were characterized by XRD and SEM spectrometer.

\section{Materials and Methods}

\subsection{Chemicals}

All chemicals used in this research were of analytic grade type and it includes:- Copper chloride di hydrate $\left(\mathrm{CuCl}_{2} \cdot 2 \mathrm{H}_{2} \mathrm{O}\right)$, Glacial acetic acid $\left(\mathrm{CH}_{3} \mathrm{COOH}\right)$, Sodium hydroxide $(\mathrm{NaOH})$, Neutral alumina $\left(\mathrm{Al}_{2} \mathrm{O}_{3}\right)$ and distilled 
water.

\subsection{Methods}

2.2.1. Preparation of CuO Nanoparticles by Sol-Gel Method Aqueous solution of $\mathrm{CuCl}_{2} .2 \mathrm{H}_{2} \mathrm{O}(0.2 \mathrm{M})$ was prepared in cleaned round bottom flask. $1 \mathrm{ml}$ of glacial acetic acid was added to the above aqueous solution and was heated to $100{ }^{\circ} \mathrm{C}$ with constant stirring. $8 \mathrm{M} \mathrm{NaOH}$ was added to above heated solution till the $\mathrm{pH}$ reached 7 . The color of the solution turned from green to black immediately and a large amount of black precipitate was formed immediately.

The precipitate was centrifuged and washed 3-4 times with distilled water. The obtained precipitate was dried in air for 24 hours. This powder was further used for the characterization of $\mathrm{CuO}$ nanoparticles.

\subsubsection{Preparation of (CuO Supported by Alumina) Catalyst $\left(\mathrm{CuO} / \mathrm{Al}_{2} \mathrm{O}_{3}\right)$}

Aqueous solution of $\mathrm{CuCl}_{2} \cdot 2 \mathrm{H}_{2} \mathrm{O}(0.2 \mathrm{M})$ was prepared in cleaned round bottom flask. $1 \mathrm{ml}$ of glacial acetic acid was added to above aqueous solution and heated to $100{ }^{\circ} \mathrm{C}$ with constant stirring. $8 \mathrm{M} \mathrm{NaOH}$ was added to above heated solution till $\mathrm{pH}$ reaches to 7 . The color of the solution turned from green to black immediately and the large amount of black precipitate was formed immediately

While the black precipitate was formed about $10 \mathrm{~g}$ of neutral alumina was added with constant stirring for one hour the precipitate was centrifuged and washed 3-4 times with distilled water. The obtained precipitate was dried in air for 24 hours.

\subsubsection{Application of Copper Oxide Supported on Alumina Catalyst in Preparation of Tetraethyl Orthosilicate}

$1 \mathrm{~g}$ of ultra-pure silicon dioxide was weighted, tiny amount of copper oxide supported on alumina catalyst was added, 20 $\mathrm{ml}$ of diethyl ether and $25 \mathrm{ml}$ of hydrochloric acid were added, and the solution was left until the precipitation was completed, the precipitate was filtered and weighted, and finally the percentage yield of the obtained product was calculated using the following equation:

$$
\text { Yield } \%=\left(\mathrm{W}_{\text {prac }} / \mathrm{W}_{\text {theo }}\right) \times 100
$$

Where:

$\mathrm{W}_{\text {prac }}$ practical weight

$\mathrm{W}_{\text {theo }}$ theoretical weigh

\subsection{Characterization}

\subsubsection{X-ray Diffraction (XRD)}

The powder sample was characterized by X-ray diffraction (XRD) (Mimi flex, Rigaku diffractometer) using $\mathrm{CuKa}$ (1 = $1.5405 \AA$ ) radiation. The average crystallite size (t) has been calculated from the line broadening using Scherrer's relation:

$$
\mathrm{D}=0.9 \lambda / \beta \cos \theta
$$

Where

$\lambda$ is the wavelength of $\mathrm{X}$-ray $\beta$ is full width of half maximum (FWHM)

$\theta$ is peak obtained angle

\subsubsection{Scanning Electron Microscope (SEM)}

The morphological and microstructure aspect of $\mathrm{CuO}$ nanoparticles were investigated by using scanning electron microscope (FESEM) dual beam field emission scanning electron microscope (LYRA3 Tescan) equipped with energy dispersive X-Ray spectrometer (EDX, oxford instruments) and transmission electron microscope (JEM2100F).

\subsubsection{Iodometric Titration to Determine Copper Percentage} Iodometric titration (oxidation of iodide)

$1 \mathrm{~g}$ of copper oxide was dissolved in $0.2 \mathrm{M}$ of $\mathrm{HCl}$ to prepare the sample.

$2.0 \mathrm{~g}$ of $\mathrm{KI}$ was added to the sample, and titrated immediately with $\mathrm{Na}_{2} \mathrm{~S}_{2} \mathrm{O}_{3}$ until the solution becomes pale yellow. Starch indicator was added, and the titration was continued until the blue color became faint. The titration was completed; the disappearance of the blue $s t a r c h / \mathrm{I}_{2}$ color was used as the end point.

\subsubsection{Rate of Reaction for the Formation of Tetraethyl Orthosilicate}

Rate of Reaction of tetraethyl orthosilicate

The time of initially precipitate crystals was recorded, and then the rate of reaction was calculated, using following equation:

(Wt/time) $\mathrm{g} / \mathrm{sec}$.

The same procedure was applied in determine the rate of reaction of silicon alkoxide by using catalyst.

\section{Results and Discussion}

\subsection{Preparation of Copper Oxide NPs by Sol-gel metHod}

There are various techniques to prepare Nano crystals e.g. sputtering, laser ablation, cluster deposition, sol-gel method etc. In the present work the synthesis of $\mathrm{CuO}$ was done by sol-gel route because this method is easy and economical. The sol-gel process involves the formation of colloidal suspension (sol) and gelation of the sol to form a network in continuous liquid phase (gel). The precursors for synthesizing these colloids consist usually of a metal or metalloid element surrounded by various reactive legends

The chemical reaction is as follows:

$$
\mathrm{CuCl}_{2}+2 \mathrm{NaOH} \rightarrow \mathrm{Cu}(\mathrm{OH})_{2}+2 \mathrm{NaCl}
$$

And copper hydroxide decomposes into copper oxide on heating as follows,

$$
\mathrm{Cu}(\mathrm{OH})_{2} \rightarrow \mathrm{CuO}+\mathrm{H}_{2} \mathrm{O}
$$

The obtained $\mathrm{CuO}$ powder was finely black soft powder obtained in high yield. 


\subsection{Preparation of Copper Oxide Supported on Alumina}

The black $\mathrm{CuO}$ precipitate was change to gray brown precipitate with homogenously distribution of the powder supported metal oxide.

\subsection{Rate of Reaction (Synthesis of Tetraethyl Orthosilicate)}

Elemental silicon can't react directly with reagent but it reacts in presence of catalyst or at elevated temperature. Because Silicon atom is covered by an oxide layer that prevents its attack by chemicals. Therefore, it requires a catalyst to break down this oxide layer and activate silicon to react. Accordingly, variable catalysts have been used in this work for activation of silicon in direct synthesis of tetraethoxysilane. The reaction between elemental silicon and ethanol does not take place without using any catalyst. However, the direct synthesis of tetraethoxysilane by a direct reaction of silicon with alcohol has many advantages compared to the previous method.

From this results for any $30 \mathrm{sec}$ was formed $0.82 \mathrm{~g}$ from tetraethyl orthosilicate in using catalyst $(0.0273 \mathrm{~g}$ per sec $)$, but without catalyst formed $0.72 \mathrm{~g}$ for $90 \mathrm{sec}(0.008 \mathrm{~g}$ per sec $)$, this indicating that, the tetraethyl orthosilicate which prepared by using catalyst is better than the prepared without catalyst.

\subsection{Characterization of Copper Oxide and Copper Oxide Supported by Alumina}

\subsubsection{XRD Results of Copper Oxide and Copper Oxide Supported by alumina}

$\mathrm{X}$-ray diffraction is an easy and one of the most important characterization tools used in nanomaterial research field. Here, an important nanomaterial - copper nanoparticles has been successfully prepared by sol-Gel method in normal room temperature and its structural characterizations have been studied by important tool - X-ray diffraction.

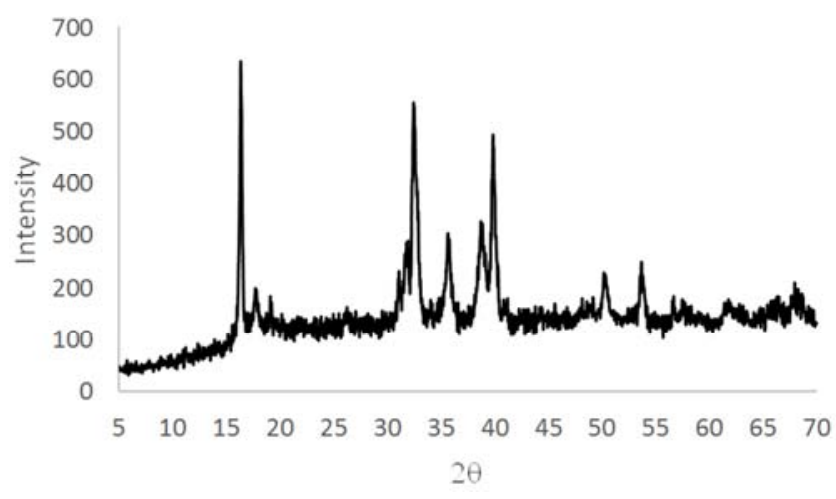

Figure 1. XRD of copper oxide.

In figure1 the results confirm nanoparticles, uniformed size less than $10 \mathrm{~nm}$.

Values of $2 \theta=(32.4 ; 35.6$ And 39.8) Have a high intensity

Planes of copper have been observed and in agreement with data obtained from the other studies from the literature review.

The 3 main peaks give a single-phase with a monoclinic structure No characteristic peaks of any other impurities such as $\mathrm{Cu}(\mathrm{OH})_{2}, \mathrm{Cu}_{2} \mathrm{O}$ was observed.

In other hand we observed in figure 2 that the copper oxide with alumina have a similar peaks of figure 1 with a clear distortion make the peaks have a low intensity

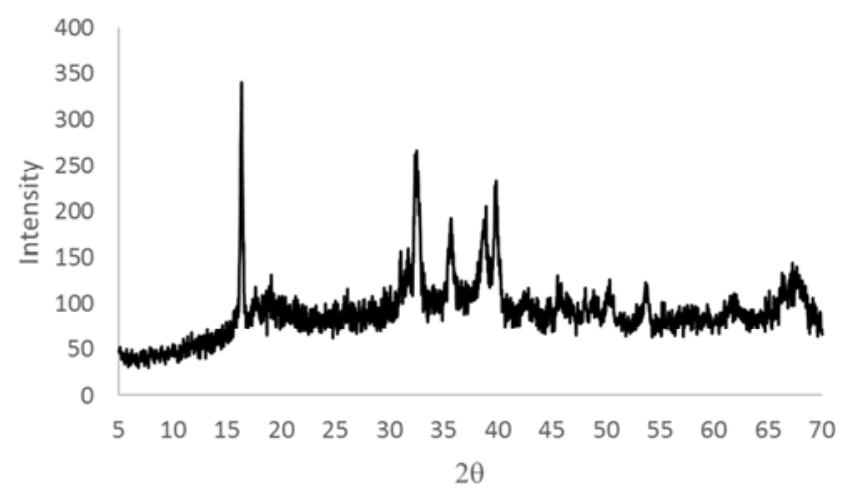

Figure 2. XRD of copper oxide supported by alumina.

\section{Calculation of Crystal Size}

The crystallite size of the prepared $\mathrm{CuO}$ NPs were calculated from the full width at half maximum (FWHM), using the Debye-Scherrer formula.

$$
t=\frac{0.9 \lambda}{B \cos \theta}
$$

Where $\mathrm{B}$ is the full width at half maximum (FWHM) of the XRD all

Peaks, $t$ is the crystallite size, $\lambda$ is the wave length of the $\mathrm{X}$-ray and $\theta$ is Bragg's angle

$\lambda=0.15405 \mathrm{~nm}$

$\theta=16.22^{0}$

$\mathrm{B}=0.9 * 3.14 / 180$ radian

From the equation $\mathrm{t}=9.19 \mathrm{~nm}$

\subsubsection{SEM Results of Copper Oxide and Copper Oxide Supported by Alumina}

SEM micrographs of the synthesized $\mathrm{CuO}$ are shown in the figure 3 (A, B, C, D, E, F and G). From the figure it is quite evident that there is no definite morphology in the sample. It seems that the particles were agglomerated and form a cluster. As the particle size calculated from the XRD is in Nano range and not getting any exact information about the surface morphology of the sample from the SEM micrograph. The morphology observed in the sample not showing any hard grains which gives the idea that size of the particle is small and has a single phase

In figure 4 (A, B, C, D, and F) the observed morphology of $\mathrm{CuO}$ in figure 3 is greatly changed in the photograph of copper oxide support in alumina. 

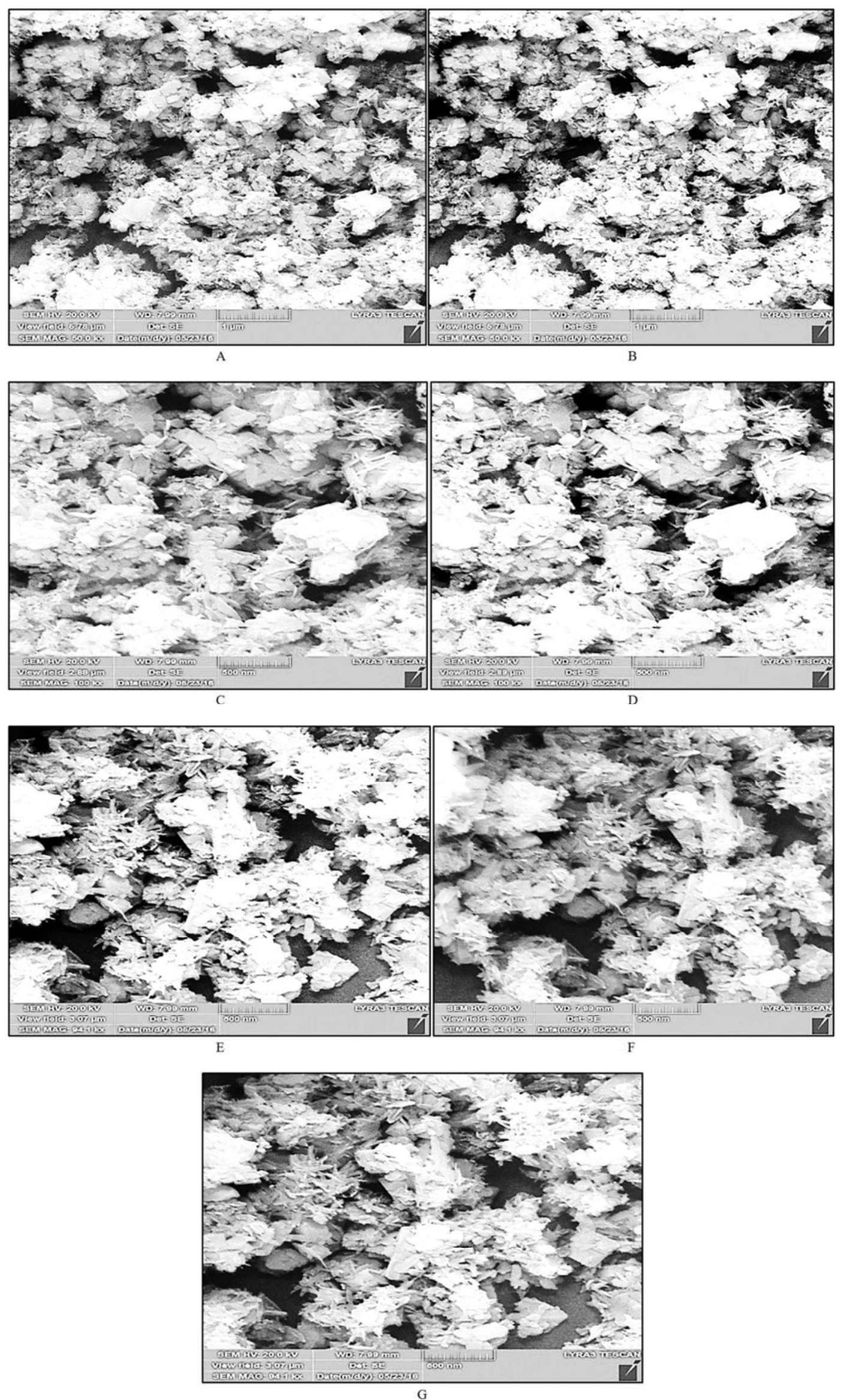

Figure 3. $(A, B, C, D, E, F$ and $G)$ : SEM Result of Copper Oxide NPS. 

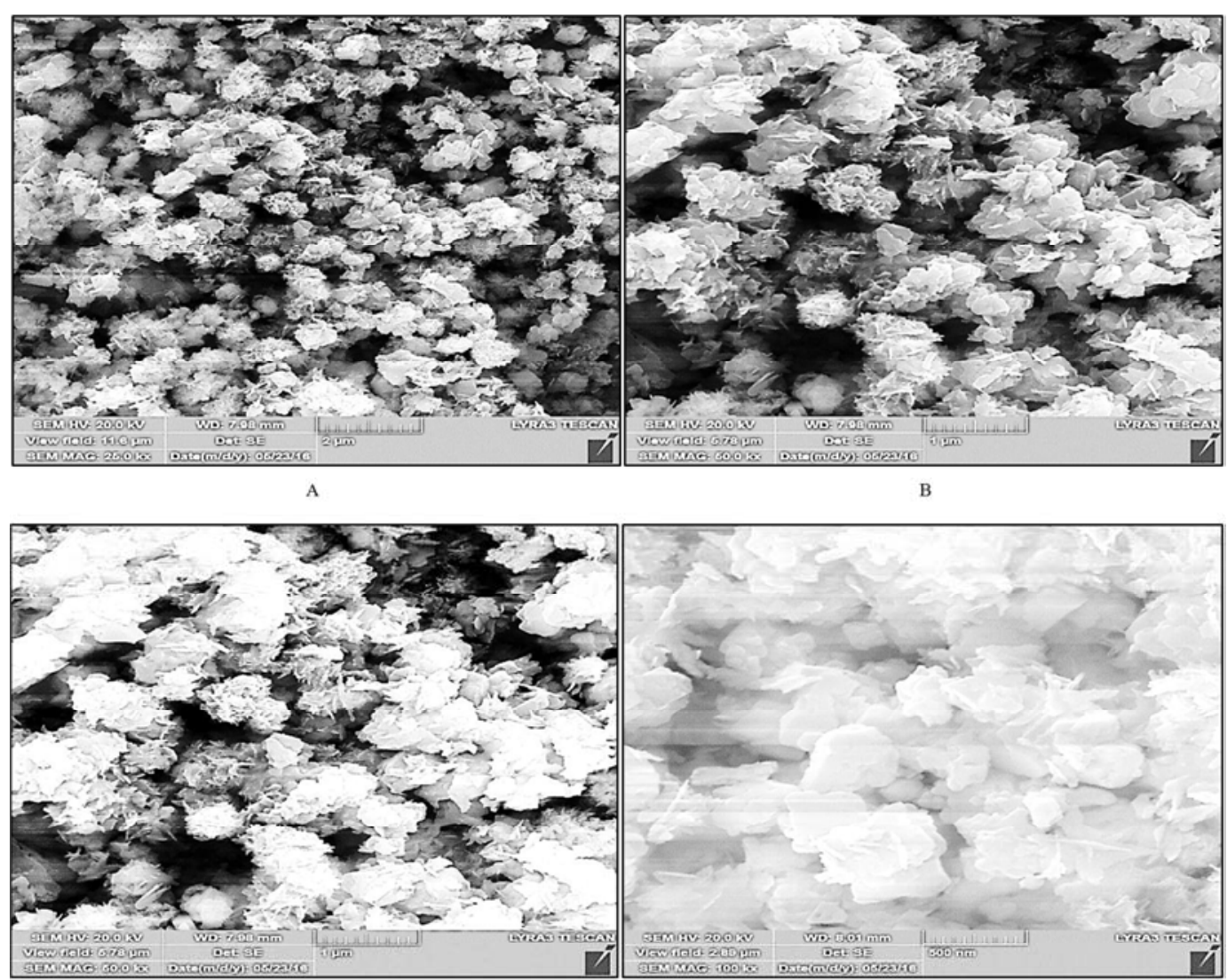

C

$\mathrm{D}$

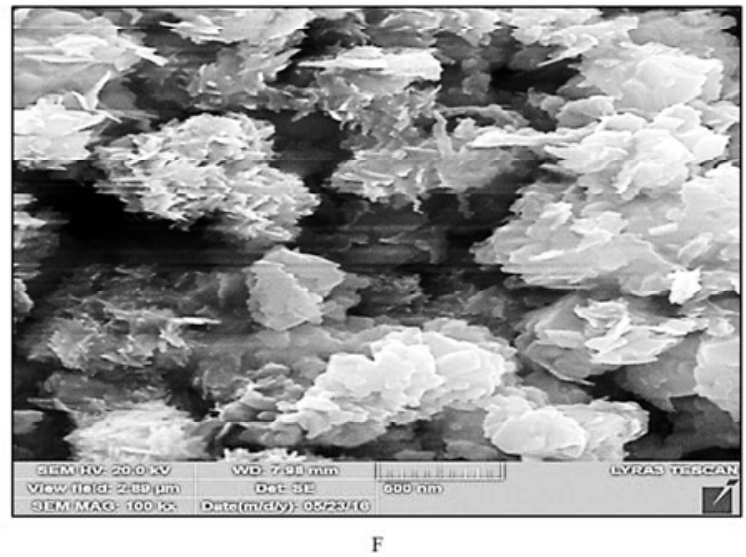

Figure 4. $\left(A, B, C, D\right.$ and F): SEM Result of $\mathrm{CuO} \mathrm{NPs} / \mathrm{Al}_{2} \mathrm{O}_{3}$.

\subsubsection{Determination of Copper Oxide Percentage}

By using titration method the percentage of copper in the sample of copper oxide NPs was found $=67.38 \%$

This result was closed with the standard review which is $70-75 \%$ [5].

The chemical Equation

$$
\begin{gathered}
2 \mathrm{Cu}(\mathrm{Cl})_{2}+4 \mathrm{KI} \rightarrow 2 \mathrm{CuI}(\text { solid })+\mathrm{I}_{2}+4 \mathrm{KCl} \\
2 \mathrm{Na}_{2} \mathrm{~S}_{2} \mathrm{O}_{3}+\mathrm{I}_{2} \rightarrow 2 \mathrm{NaI}+\mathrm{Na}_{2} \mathrm{~S}_{4} \mathrm{O}_{6}
\end{gathered}
$$

\subsection{Practical Weight of Tetraethyl Orthosilicate}

\subsubsection{By Using Catalyst}

The obtained practical weight of Tetraethyl orthosilicate was $0.82 \mathrm{~g}$ and the calculated percentage yield was $30 \%$, this result is in agreement with the expected yield [6].

\subsubsection{By Direct Method Without Catalyst}

The obtained practical weight of Tetraethyl orthosilicate was $0.72 \mathrm{~g}$ and the calculated percentage yield was $26.6 \%$ [7].

\section{Conclusion}

Copper nanoparticles synthesized using SOL- GEL method is a simple and environmental benign method. This method has many advantages such as economic viability, ease to scale up and less time consuming. In this research Copper oxide nanoparticles was prepared and used as catalyst 
for synthesis of Tetraethyl orthosilicate after supporting in alumina.

The experiment revealed that the presence of copper nanoparticles is necessary for increasing the rate of the reaction.

\section{References}

[1] E. P. Wolhfarth. (1980), Ferromagnetic Materials, Vol. II, North-Holland, Amsterdam, New York, Oxford, Tokyo.

[2] M. Shahmiri, N. A. Zowa Ibrahim, N. Zainuddin, Nilofarasim, B. Bakhtyar, A Zaharim, K Sopian (2013), Preparation and characterization of copper oxide nanoparticles. International Journal of ChemTech Research 9 (3): 2224-3496.
[3] M. I. El-Nahhal. M. Shehata. Zourab, S. Fawzi, Kodeh, M. Semane, I. G. Florence.(2012), Int. Nano Lett., 2: 62-67.

[4] Chang. Ya-Nan, Mingyi Zhang, Lin Xia, Jun Zhang, (2012), Materials, 5: 2850-2871.

[5] H. Wyne Richardson (1997), handbook of copper compounds and applications, USA South Carolina, NY. BASEL. Hong Kong, ISBN 0-8247-8998-9.

[6] A. H. E. Yousif, O. Yousif, Alhusseinb, A. M. Elgorashi., M. S. Ali and W. I. Eldogdugd. (2016). Synthesis and Characterization of Organic Silicates Using Appropriate Catalysts. International Journal of Innovative Science, Engineering \& Technology, 3 (1): 2348-7968.

[7] D. R. Andersonin, (1974). Analysis of silicones. A. Lee Smith, editor, Wiley-Interscience, New York, Chapter 10. 